\title{
CIV. Primary and secondary $\gamma$ rays
}

\section{D.C.H. Florance M.A. M.Sc.}

To cite this article: D.C.H. Florance M.A. M.Sc. (1910) CIV. Primary and secondary $\gamma$ rays, Philosophical Magazine Series 6, 20:120, 921-938, DOI: 10.1080/14786441008636985

To link to this article: http://dx.doi.org/10.1080/14786441008636985

曲 Published online: 21 Apr 2009.

Submit your article to this journal $\pi$

Џ Article views: 3

Q View related articles $₫$

4 Citing articles: 7 View citing articles 둔 
chemical point of view in pointing out the existence of chemical relations. Thus if it is found that certain relations connect the values of $\frac{T}{\Sigma \sqrt{m_{1}}}$ of certain chemical compounds, we might expect that some corresponding chemical relations exist. The determination of the critical constants of chemical compounds, especially the critical temperature, becomes therefore of great importance. A more complete list of the critical constants than the one at present available may lead to the discovery of a number of other properties of the quantity $\frac{T}{\Sigma \sqrt{m}_{l}}$ corresponding to certain chemical proparties, besides those given in this paper.

There appears no obvious reason why the quantity $\frac{\mathrm{T}_{c}}{\mathrm{~S} \sqrt{m_{1}}}$ of a substance should be so closely connected with its chemical properties. We may state this quantity in a different way, but that hardly tbrows any light on the subject. The kinetic energy of a molecule is proportional to the temperature, and we may therefore define this quantity as the ratio of the kinetic energy of a molecule at the critical temperature to its chemical attraction at a given distance.

Further relations of the quantity with physical and chemical quantities will be given in subsequent papers. A comparison of the various results obtained will probably lead to a definite explanation why the properties of this quantity run parallel with the chemical properties.

Cambridge, July 20, 1910.

CIV. Primary and Secondary $\gamma$ Rays.

$B y$ D. C. H. Florance, M.A., M.Si.*

W ${ }^{\text {HEN }} \gamma$-rays strike a body it is well known that a secondary radiation is produced. Part consists of a corpuscular radiation similar in character to $\beta$-rays; and part consists of a very penetrating radiation similar in chiracter to the primary $\gamma$-rays. Eve $\uparrow$ first proved that these penetrating secondary rays were of the $\gamma$-ray type. Kleeman $\ddagger$

* Communicated by Prof. E. Rutherford, F.R.S.

$\dagger$ Phil. Mag. Dec. 1904.

† Phil. Mag. May 1908 .

Plit. Mag. S. 6. Vol. 20. No. 120. Dee. 1910. 
examined closely the radiations from various metals, and from his results concluded that the primary and secondary $\gamma$-rays could be divided into several homogeneous groups. Madsen*, by a study of the "emergent" radiation, $i$. e. the radiation emitted from a screen in the direction of the primary $\gamma$ rays, divided the primary radiation into two homogeneous groups. One was "hard" or very penetrating, and the other a solt group or one easily absorbed. He has shown that there exists a marked lack of symmetry in the quantity of secondary radiation emitted from the two sides of the plate, and in some cases a considerable difference in the penetrating power of the radiation. $\mathrm{He}$ considers that this secondary radiation is derived from the primary by a scattering process.

The question of the distribution and character of the secondary $\gamma$-rays is very complicated, and although a large amount of work has been done, many points still remain to be settled. It is of great importance, for example, to settle whether the secondary radiation of the $\gamma$-ray type is merely part of the primary rays which have been scattered in their passage through matter, or is a true secondary radiation excitsd by the passage of the $\gamma$-rays through matter. In the latter case, it is to be expected that the secondary $\boldsymbol{\gamma}$-rays would differ in quality from the primary. One of the main difficulties of the subject is the apparent complexity of the primary $\gamma$-rays, to which attention has been drawn by Five, Kleeman, and Madsen. Soddy has found under special conditions that the $\gamma$-rays from radium are absorbed according to an exponential law, and has concluded consequently that the radiations are homogeneous. This view is, however, difficult to reconcile with the evidence obtained by a study of the recondary $\gamma$-rays $\dagger$.

The following experiments were undertaken to see if any conclusive evidence could be obtained to settle between these hypotheses. 'The results given in this paper extend and somewhat modify those obtained by Madsen. The $\gamma$-rars appear to be entirely heterogeneous, and the terms "hard" and "soft" can only be used for convenience and not to denote two distinct groups of homogeneous rays.

The paper consists of two parts:-

I. A short investigation of the initial absorption of $\gamma$-rays by lead under ordinary experimental conditions.

* Phil. Mag. March 1909.

† Note recent letters: Kleeman, Phil. Mag. July 1910; Soddy, Phil. Mag. A ugust 1910. 
II. Secondary $\gamma$ radiation.

(1) The distribution of secondary $\gamma$ radiation :

(a) produced by different thicknesses of the same material ;

(b) produced by different materials.

(2) The quality of the secondary $y$ radiation.

The variation of quality with

(a) Position of electroscope.

(b) Material of radiator.

(c) Thickness of radiitor.

(d) Area of radiator.

(e) Screening of radium.

(3) A discussion of the question whether the secondary $\gamma$-rays are true secondary rays or scattered primary rays.

\section{Initial Absorption of $\gamma$ Rays.}

When $\gamma$-rays are absorbed by a substance such as lead it has been observed by most experimenters that the coefficient of absorption decreases with an increase in thickness of the ahsorbing material. This has been generally explained by assuming the original radiation to be heterogeneous, and consequently the softer radiation to be cut out more in proportion than the harder radiation. That the $\gamma$-rays from radium are heterogeneous is no doubt true, but the above assumption requires modification to explain all the cases that are likely to arise. Observers do not agree in the exact values to be assigned for the initial absorption of $\gamma$-rays. A few experiments were performed to see what was the reason of this divergence.

Apparatus.

The electroscope was of lead, $3 \mathrm{~mm}$. thick and $7 \mathrm{~cm}$. cube. The top, bottom, and the two sides of the electroscope containing the windows were surrounded in lead about $1 \mathrm{~cm}$. thick. The face through which the $\gamma$-rays penetrated was $3 \mathrm{~mm}$. thick. A screen of lead $\cdot 7 \mathrm{~cm}$. could be used to test the quality of the radiation. The quality is determined by calculating $\lambda$ the absorption coefficient of this $\cdot 7 \mathrm{~cm}$. of lead from the relation $I_{t}=I_{0} e^{-\lambda t}$, where $I_{0}$ is the leak in the electroscope before the lead screen is placed in position. The electroscope was supported on an iron pipe about $1 \frac{1}{4}$ inches in diameter. The radinm was placed near the edge of a table, and in some cases the lead screen was supported $3 \mathrm{P} 2$ 
by string from a board overbead. Thus care was taken to prevent secondary radiation from surrounding bodies. In these experiments the leak of the electroscope was fairly large, and no difference was observed when the small glass windows were screened by lead.

Radium (20 mgrs. Ra) was placed $56 \mathrm{cms}$. from the electroscope. The absorption coefficient was measured for narrow pieces of lead $\cdot 172 \mathrm{~cm}$. thick placed against the radium. The length, breadth, and thickness were $(11 \times 3 \cdot 5 \times \cdot 172) \mathrm{cm}$.

\begin{tabular}{|c|c|c|c|c|}
\hline \multicolumn{5}{|c|}{ Thickness of Screen. } \\
\hline Thickness \{ & $\begin{array}{l}\cdot 0 \\
\cdot 172 \mathrm{~cm} .\end{array}$ & $\begin{array}{l}516 \\
.684 \mathrm{~cm} .\end{array}$ & $\begin{array}{c}.854 \\
1.04 \mathrm{~cm}\end{array}$ & $\begin{array}{l}1.38 \\
1.55 \mathrm{~cm} .\end{array}$ \\
\hline$\lambda$. & $\cdot 99$ & $\pi 0$ & 65 & -58 \\
\hline
\end{tabular}

From this experiment it would seem that the lead screen simply cut out the less penetrating $\gamma$-rays.

Compare these results with those obtained by other investigators.

\begin{tabular}{|c|c|c|c|c|c|}
\hline \multirow{2}{*}{ McClelland ${ }^{*} \ldots$} & Thickness & $\left\{\begin{array}{c}.8 \\
1.05 \mathrm{~cm}\end{array}\right.$ & $\begin{array}{l}1.05 \\
1.3 \mathrm{~cm} .\end{array}$ & $\begin{array}{l}1.3 \\
1.8 \mathrm{~cm} .\end{array}$ & $\begin{array}{l}1 \cdot 8 \\
2 \cdot 3 \mathrm{~cm}\end{array}$ \\
\hline & $\lambda \ldots .$. & 64 & .56 & $\cdot 48$ & $\cdot 44$ \\
\hline \multirow{2}{*}{ Tuomikoski†... } & Thickness & $\left\{\begin{array}{l}\cdot 4 \\
1 \cdot 0 \mathrm{~cm} .\end{array}\right.$ & $\begin{array}{l}1 \cdot 0 \\
2 \cdot 2\end{array}$ & $\begin{array}{l}2 \cdot 2 \\
5 \cdot 4\end{array}$ & $\begin{array}{r}54 \\
12.0\end{array}$ \\
\hline & $\lambda \ldots \ldots$. & 70 & $\cdot 58$ & .52 & $\cdot 50$ \\
\hline \multirow[t]{2}{*}{ Eve $\neq \ldots \ldots \ldots \ldots$} & Thickness & $\left\{\begin{array}{c}64 \\
1 \cdot 21 \mathrm{~cm}\end{array}\right.$ & $\begin{array}{l}1.21 \\
1.79\end{array}$ & $\begin{array}{l}1 \cdot 79 \\
2 \cdot 36\end{array}$ & $\begin{array}{l}2 \cdot 4 \\
3 \cdot 0\end{array}$ \\
\hline & $\lambda \ldots \ldots$ & .57 & 56 & -46 & 46 \\
\hline
\end{tabular}

* Phil. Mag. July 1904. † Phys. Zeit. June 1909. $\quad \ddagger$ Phil. Mag. A pril 1906.

As we have seen, Soddy has concluded that the true value for the absorption coefficient right from the initial stage should be $\lambda=-50$.

A glance at the above results shows discrepancies much too large to be ascribed to experimental errors.

The radium still in the same position is surrounded with lead. A piece $(11 \times 5 \times 1.4) \mathrm{cm}$, is placed directly in front of the radium and lead $1.5 \mathrm{~cm}$. thick placed at the side. 
The absorption coefficient is now determined for a screen of lead $(11 \times 11 \times \cdot 7) \mathrm{cm}$, when it is placed against the lead screen in front of the radium; and secondly, when it is placed against the electroscope.

$$
\begin{aligned}
& .7 \mathrm{~cm} \text {. against the lead screen } \lambda=\cdot 50 \\
& .7, \quad \text {, electroscope } \lambda=.55 .
\end{aligned}
$$

This effect seemed to be caused by the secondary radiation emitted by the screen.

A narrow screen $3.4 \mathrm{~cm}$. wide and $1.3 \mathrm{~cm}$. thick is placed in front of the radium. A lead screen $(13 \times 13 \times 1 \cdot 1) \mathrm{cm}$. is divided into three strips. One of these narrow strips is placed against the lead screen in front of the radium, and the coefficient of absorption is thus determined.

The apparent absorption coefficient $\lambda=\cdot 51$. The two other strips are now added to continue the plate, and for this large plate $\lambda=\bullet 46$. The side portions of the screen which are added in this latter case do not cut off any of the direct primary radiation from the electroscope. They add, however, the secondary radiation due to the passage of the primary radiation. Hence the area of the absorbing screen will modify the value of the coefficient of absorption. Experiments also show that bodies in the neighbourhood, from which a secondary radiation can be produced, will cause a variation in the value of results. The secondary radiation from the air due to the passage of the primary radiation would most probably be very small.

\section{Importance of secondary $\gamma$-rays in the measurement of the absorption coefficient of primary $\boldsymbol{\gamma}$-rays.}

The radium is kept in a constant position $80 \mathrm{~cm}$. from the electroscope. A large screen $(20 \times 20 \times 1 \cdot 01) \mathrm{cm}$. can be placed in any position between the radium and electroscope. A lead scrcen $7 \mathrm{~cm}$. thick is placed against the electroscope to test the quality of the radiation.

\begin{tabular}{|c|c|c|c|}
\hline Posilion of large screen ... & Position I. & Position II. & Position III. \\
\hline Distance from electroscope ... & $77.5 \mathrm{~cm}$. & $66 \mathrm{~cm}$. & $1 \mathrm{~cm}$. \\
No screen ngainst electroscope & $5.05 \mathrm{div} . / \mathrm{min}$. & $4.65 \mathrm{div} . / \mathrm{min}$. & $4.29 \mathrm{div} . / \mathrm{min}$. \\
Sereen against electroscope... & $3.26 \mathrm{div} . / \mathrm{min}$. & $3.17 \mathrm{div} . / \mathrm{min}$. & $282 \mathrm{div} . / \mathrm{min}$. \\
Absorption coefficient ......... & $\lambda=62$ & $\lambda=.54$ & $\lambda=.60$ \\
\hline
\end{tabular}

It will be seen that the magnitude of the leak and also the absorption coefficient of the radiation change considerably 
with the position of the screen. In position I. the large screen does more than cut out the direct radiation--it adds the secondary radiation scattered from all parts of its volume. This quantity will decrease as the solid angle subtended by the screen at the radium decreases. On the other land, as the screen approaches the electroscope it would be expected that the secondary radiation emitted would have an increased effect. Results point to the general conclusion that the production of the secondary radiation is the chief cause for the variation in the value of the absorption coefficient determined under different experimental conditions. The initial rapid change of the absorption coefficient is no doubt due to the rapid absorption of the soft portion of the primary radiution.

In connexion with the secondary $\gamma$-rays a few experiments were performed to test the quality and the amount of the primary $\boldsymbol{\gamma}$-rays passing through various materials.

In this case a lead electroscope $6 \mathrm{~cm}$. thick was used. The thickness of absorbing screen was $624 \mathrm{~cm}$. of lead, which was placed against the electroscope. The $20 \mathrm{mgrs}$. of radium was surrounded by $208 \mathrm{~cm}$. of lead. (See fig. 1.)

Fig. 1 .

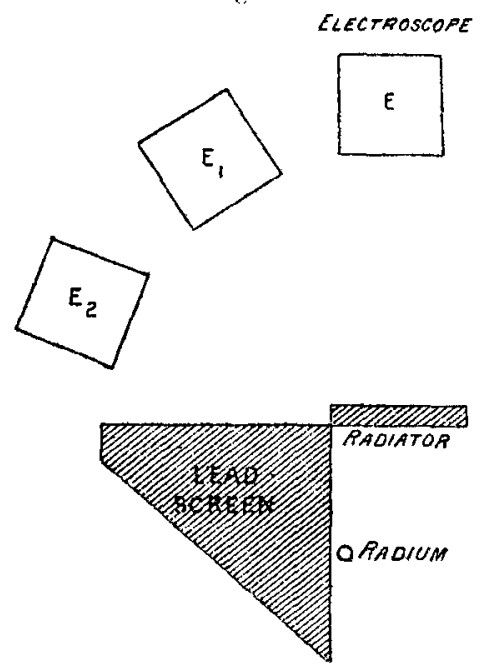

$\mathrm{E}$ is the electroscope in the position of direct radiation.

$E_{1}$ and $E_{2}$ are positions of the electroscope for the measurement of secondary radiation.

The radium cannot be placed symmetrically as regards the radiator as it is required to have $\mathrm{E}_{1}$ as near the position $\mathrm{E}$ as possible without intercepting the direct radiation. 
The different radiators are supported by string.

$$
\begin{array}{cl}
\text { No radiator } & \lambda=\cdot 71 \\
5 \text { cms. of carbon } & \lambda=\cdot 68 \\
10 \text { cms. of carbon } & \lambda=\cdot 65 \\
2 \text { cms. of iron } & \lambda=\cdot 65 \\
5 \text { cms. of iron } & \lambda=\cdot 59 \\
.416 \mathrm{~cm} \text { of lead } & \lambda=\cdot 625
\end{array}
$$

The area of the radiator is constant $(11 \times 11) \mathrm{cm}$. Each radiator has had, therefore, a hardening effect. It will be shown later that the relative values of these absorption coefficients remain the same for each position of the electroscope.

Consider now the amount which passes through these radiators. In fig. 2 are plotted the curves showing the scale-dir./min. Fig. 2.

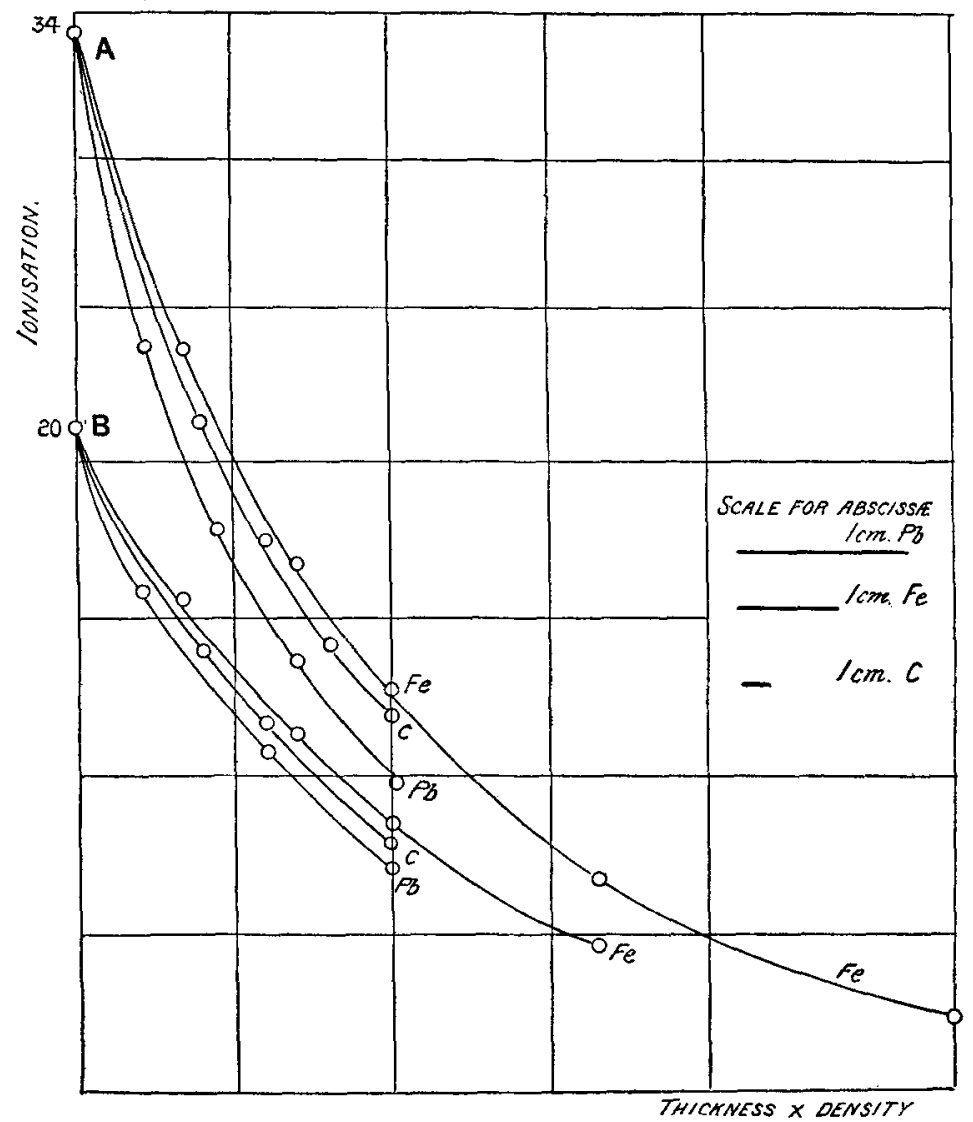

Group A shows absorption of the direct $\gamma$ rays through different thicknesses of three radiators. Side of electroscope is $6 \mathrm{~mm}$. thick. Group $\mathrm{B}$, side of electrosenpe is $12 \mathrm{~mm}$. thick. 
relation between thickness of radiutor $\times$ the density, and the amount of radiation passing through as measured by the electroscope in scale-divisions per minute. It $w$ ill be noticed that the curve for carbon falls between thosc for iron and lead. This is unexpected, but it may be due to the fact that the radiation has to pass through the side of an electroscope $6 \mathrm{~mm}$. thick, which would cut out the radiations emitted from different radiators in a varying degree. The second group of curves shows the effect of placing $6 \cdot 24 \mathrm{~mm}$. of lead against the electroscope. The initial drop is not so great in this case. For equal weights per unit area the amount of radiation passing through varies for different substances.

A comparison in the following table is made of the quantities passing through different radiators which give the same coefficient of absorption when examined by lead.

\begin{tabular}{|c|c|c|c|c|}
\hline Radiator. & Thickness. & $\begin{array}{c}\text { Mass per unit area } \\
\text { in grs. }\end{array}$ & Quantity. & $\lambda$. \\
\hline Carbon ... & $10 \mathrm{cm.}$ & 22 & 14 & .65 \\
Iron ..... & $2 \mathrm{cm.}$ & 14.7 & 17 & 65 \\
Lend ...... & $.25 \mathrm{~cm}$. & 2.8 & 26 & .65 \\
\hline
\end{tabular}

A greater amount of the primary radiation passes through the lead than through the carbon, yet the absorption coefficient is the same in both cases. There is no difficulty in explaining this if we assume that the $\gamma$-rays of radium are heterogeneous. For the sake of clearness consider the $\gamma$-rays divided into a hard and a soft group. Probably the soft group is in excess of the hard group. The results of experiments in the second part of this paper show that there is more scattering in a substance like carbon than in lead. The relative amount of scattering and of absorption of the two groups will most likely vary according to the material of the radiator. It is well known that lead cuts out a soft radiation much more rapidly than does a similar weight of iron. Therefore, when the primary radiation strikes the lead radiator, the softer portion will be cut out much more in proportion to the harder than in the case of the carbon radiator. If a radiator produces a scattering of the primily radiation, then the sorting out process will be simply a difference in degree for the two groups by different radiators. There is no need to suppose there has been a change in type of the primary radiation. 
II. SEcondary $\gamma$ Rays.

(1) The Distribution of Secondary $\gamma$ Radiation.

Apparatus. - The electroscope was of lead $3 \mathrm{~mm}$. thick and $7 \mathrm{~cm}$. cube. In the first experiments, it was supported on a wooden arm which could be revolved so that the electroscope moved round the are of a circle of radius $25 \mathrm{~cm}$. The centre of this circle was approximately the centre of the radiator. The radium, abont 300 mgrs.* of $\mathrm{RaBr}_{2}$, was contained in a platinum vessel, and the electroscope was screened from the direct radiation by a mass of lead. The arrangeirent was similar to that shown in fig. 1. The radiator consisted of iron plates $11.1 \mathrm{~cm}$. sipuare. The electroscope was turned into the different positions, and the readings taken with and div./2oin.

Fig. 3 .

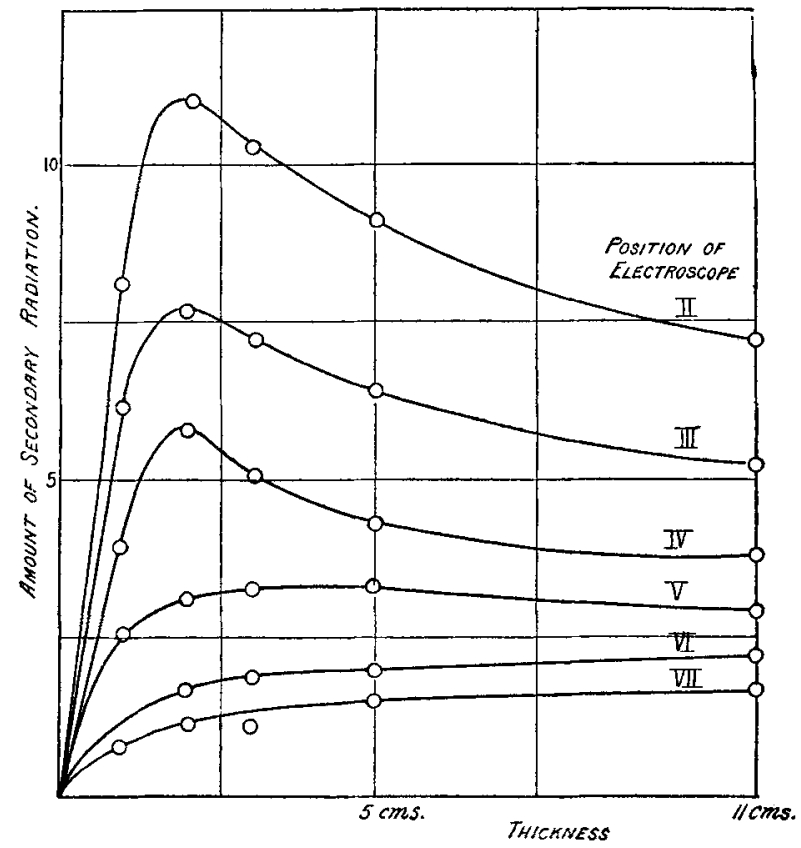

Relation between amount of secondary radiation and thickuess of iron radiator.

without the radiator. Seven positions of the electroscope are taken; the first one measures the direct radiation and the last one the secondary radiation at right angles to this. The other positions are intermediate.

In $f g .3$ curves are plotted showing the effect of varying

* This was kindly lent for the purpose by Professor liutherford. It was sealed up in order to determine the rate of production of telium from it. 
the thickness of radiator from $1.05 \mathrm{~cm}$. to $11 \mathrm{~cm}$. for each position of the electroscope round a quadrant of a circle.

Eve has shown (Phil. Mag. Dec. 1904) that for an increase in thickness of radiator, the emergent secondary $\gamma$ radiation increases rapidly till it reaches a maximum, and then it decreases. The curve thus obta'ned can be expressed mathematically by the difference of two exponentials. Madsen (Phil. Mag. March 1909) has shown the same effect. The "incident" secondary $\gamma$ radiation, $i$. $e$. the radiation turned back in its path, has also been shown to be represented hy an expression $K\left(1-e^{-\lambda_{2} d}\right)$, where $K$ is a constant, $\lambda_{2}$ the coefficient of absorption of this secondary radiation, and $d$ the thickness of the plate. Experimenters in attacking this problem have kept their ionization vessel in one position and have made it large to obtain the greatest secondary effect. With $300 \mathrm{mgrs}$. of $\mathrm{RaBr}_{2}$ there was sufficient secondary radiation to allow measurements to be made with a small electroscope and to be carried out ronnd the arc of a circle. Hence it was found that instead of a sharp line of demarcation between the emergent and incident secondary $\gamma$ radiation, the one gradually changed into the other. Curves illustrating this would change in form from that represented by $\left(e^{-\lambda d}-e^{-\lambda_{1} d}\right)$ to $\left(1-e^{-\lambda_{2} d}\right)$.

Considering the complexity of the radiation and the imperfections of experimental arrangements, it is not to be expected that there would be any simple mathematical relation between the quantities measured; and the equations proposed by former experimenters are certainly inadequate.

Relation between the amount of srcondary radiation and position of electroscope for certain thicknesses of radiator (fig. 4).

In these curves for each thickness of radiator the amount of secondary radiation is plotted radially. By continuing the curves an approximation can be obtained of the amount of the secondary radiation which passes through in the direction of the primary radiation, and also of the amount of "incident" secondary radiation. A similar approximation can be obtained from fig. 3 .

It is important to notice that a considerable portion of the total $\gamma$ radiation striking the radiator is converted into secondary. For instance, the leak in the electroscope when there is no radiator is $215 \mathrm{div} . / \mathrm{min}$. The leak when there is a radiator of iron $2 \cdot 1 \mathrm{~cm}$. thick is $103 \mathrm{div} . / \mathrm{min}$. When the electroscope is in a position just outside the direct radiation the leak is $11 \mathrm{div} / \mathrm{min}$. With the present arrangement it is difficult to determine the total quantity of secondary 
radiation even approximately; but by integrating over the distributed curves there appears to be about 20 to 30 per cent. of the ionization due to the secondary radiation emitted from the radiator.

\section{Fig. 4.}

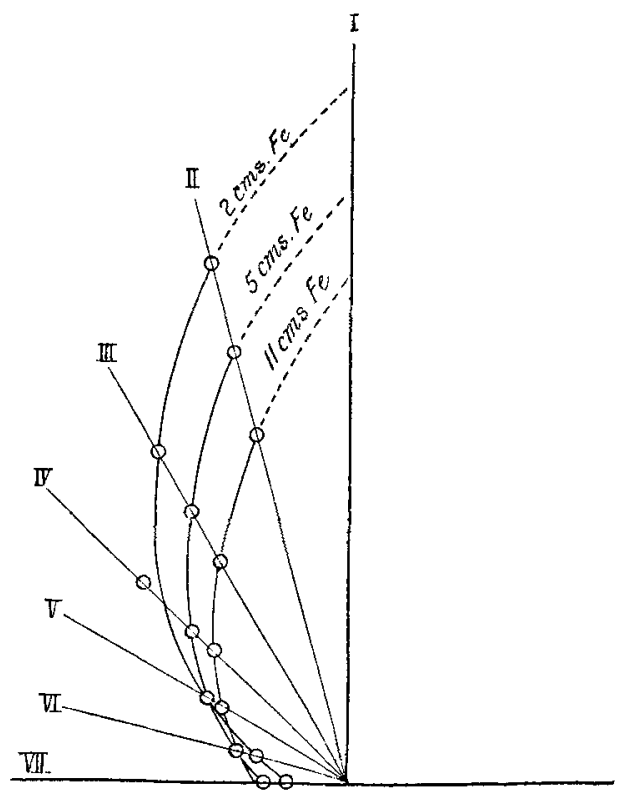

Position of electroscope.

Curves showing relation between position of electroscope and the amount of secondary radiation when the thickness is constant for each curve.

A study of the curves shows that as the thickness of radiator increases the point $A$ will approach 0 more rapidly than the points on the radial lines. It is not desirable at present to attempt to attach much meaning to the exact form of these curves, as it is possible that the shape wonld vary with the arrangement of the apparatus. The radium could not be placed symmetrically with respect to the radiator, but had to be placed against the lead screen. The gradual change in volume of the radiator due to a change in thickness from 1.05 to $11 \mathrm{~cm}$. undoubtedly has a disturbing influence.

It was thought possible that these results might be affected by secondary radiation from surrounding bodies, quite apart from the radiator itself. To test this point and to examine 
the quantity of radiation produced by different radiators the apparatus was set up afresh. A new electroscope was made of similar dimensions to the original one, but the thickness of the sides was $6 \mathrm{~mm}$. A lead screen was ilso made for the small glass windows and a lead cap for the ebonite support of the leaf system. The electroscope was supported on an iron pipe so that it could be turned round an arc of a circle. The radium (20 mgrs.) was surrounded by $2.08 \mathrm{~mm}$. of lead. The radiators were supported by string from a beam overhead, so that secondary radiation from surrounding bodies was reduced to a minimum. The arrangement is the same as shown in fig. 1 .

The direct radiation w.es first measured through the various radiators. The results were plotted with the ionizations in the electroscope as ordinates and the weight per unit area as abscissæ. These curves (fig. 2) have already been jeferred to.

To examine the secondary radiation two definite positions were taken and the results plotted in figs. 5 and 6 .

Fig. 5.

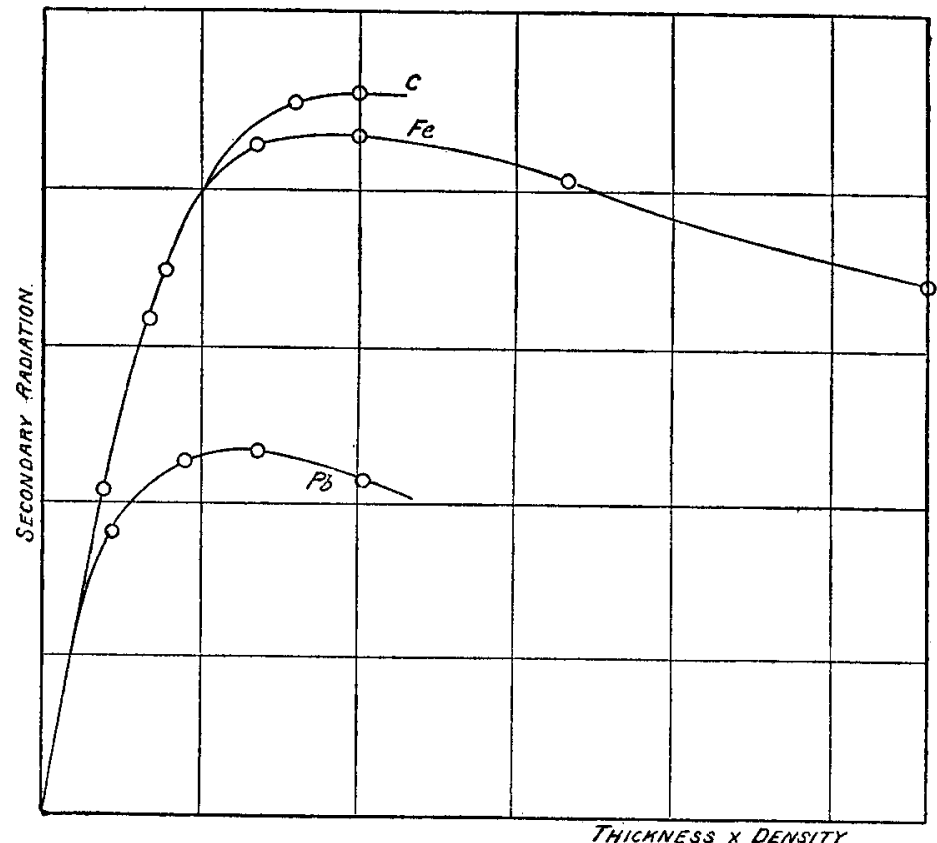

ISlectroscope turned through angle 25. Comparison of amount of secondary radiation for different thicknesses of different materials. 
Fig. 6.

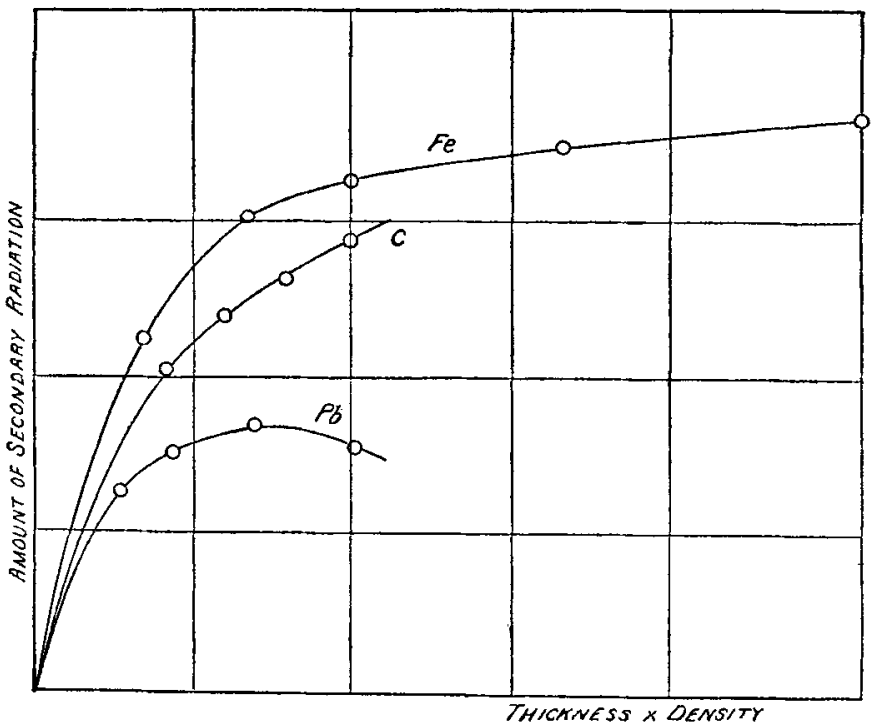

Electroscope at an angle 55०. Comparisan of amount of secondary radiation for different thicknesses of different materials.

Position I. The angle between the normal position and this position is approximately $25^{\circ}$. The carbon radiator produces more secondary radiation than does iron or lead.

Position 11 . The angle is approximately $55^{\circ}$. In this case the curve for carbon has fallen below that for iron, and even after $12.5 \mathrm{~cm}$. of carbon the maximum amount of secondary radiation had not been reached. Lead reaches its maximum value and then decreases.

A quantitative relation between the amoun?s of secondary radiation emitted by different radiators was looked for, but no evidence of such a relation has been discovered. The absorbing action of the $6 \mathrm{~mm}$. side of the electroscope would tend to mask any relation. It seemed probable, ton, that variations in the amount of secondary radiation would bo produced according to the experimental arrangement. In the present case, the volume of a certain weight of lead differed greatly from a simiiar weight of carbon.

This is borne out by the result of a special experiment. For example, five sheets of lead were spaced out over a distance of $8 \mathrm{~cm}$. They were held together by four thin brass rods so that they could be easily suspended in position, and 
thus they corresponded to the condition in which the large blocks of carbon were used. These readings were compared with those obtained with five similar sheets of lead tied together. For the direct radiation, the rate of leak was 2 per cent. greater in the case of the lead fastened closely together. But as the electroscope was turned round the secondary radiation from the radiator occupying the large volume produced a leak as much as 20 per cent. greater than that produced from the lead when tied together. This is what might have been expected, as the secondary radiation instead of getting absorbed has in the one case a chance of escaping, and this is more marked the further the electroscope is moved from the direct line of radiation. In the present arrangement, where the radius of the arc is about $22 \mathrm{~cm}$, the large volume of a radiator such as carbon may not give results comparable with those obtained for $\mathrm{l} \mathrm{cm}$. thick of lead.

\section{(2) The Quality of the Secondiry y Radiation.}

The apparatus, as previously explained, wis set up so as to reduce to a minimum the secondary radiation except that due to the radiator itself. A lead screen $3 \mathrm{~mm}$. thick was placed over the window so as to avoid any constant radiation that might get through them. The electroscope was in such a position, therefore, that when the radiator was placed in position none of the original radiation entering the electroscope was stopped; but there was simply an increased leak in the electroscope due to the secondary radiation produced by the radiator.

The quality or the penetrating power of the radiation was measured by placing a screen $6.24 \mathrm{~mm}$. of lead against the side of the electroscope, which was $6 \mathrm{~mm}$. thick. Readings were taken without the radiator, first without the lead screen, secondly with the lead screen; then similar readings with the radiator. A large number of readings were taken, and the mean value is given. In these experiments radium emanation was generally used as a source of $\gamma$-rays and a suitable correction was made for its decay.

The first table shows clearly that for all radiators the secondary $\gamma$ radiation gradually becomes softer as the electroscope is moved further away from the normal position; and that an increase in thickness of radiation hardens both the primary and the secondary. The ratio of the absorption coefficients for any two metals or for different thicknesses of one metal keeps constant for each position of the electroscope.

For example, the quality of the direct radiation passing 
Relation between coefficients of alsorption of the secondary $\gamma$ radiation.

The area of each radiator is $(11 \cdot 1 \times 11 \cdot 1) \mathrm{cm}$.

\begin{tabular}{|c|c|c|c|}
\hline Radiator. & Direct radiation. & $\begin{array}{l}\text { Electroscope at } \\
\text { angle } 2 \%^{\circ} \text {. }\end{array}$ & $\begin{array}{l}\text { Electroscope at } \\
\text { angle } 55^{\circ} \text {. }\end{array}$ \\
\hline $5 \mathrm{~cm}$. carbon & $\begin{array}{l}\text { The coefficient of } \\
\text { absorption is } \\
=68\end{array}$ & $\begin{array}{l}\text { The coefficient of } \\
\text { absorption is } \\
=1.20\end{array}$ & $\begin{array}{l}\text { The coefficient of } \\
\text { absorption is } \\
=1.77\end{array}$ \\
\hline $10 \mathrm{~cm}$. carbon & $=65$ & $=1 \cdot 18$ & $=1 \cdot 70$ \\
\hline $2 \cdot 2 \mathrm{~cm}$. iron ... & $=6.65$ & $=1 \cdot 17$ & $=1 \cdot 68$ \\
\hline $5 \mathrm{~cm}$. iron ... & $=: 59$ & $=1 \cdot 0 \pi$ & $=1 \%$ \\
\hline$-41 t^{\circ} \mathrm{cm}$. Lead & $=625$ & $=1 \cdot 11$ & $=165$ \\
\hline
\end{tabular}

Effect of area of radiator.

\begin{tabular}{|c|c|c|}
\hline Radiator. & \multicolumn{1}{|c|}{ Area. } & Electrostope at angle $80^{\circ}$. \\
\hline 22 cm. of iron ... & $(11 \cdot 1 \times 11 \cdot 1) \mathrm{cm}$. & $\lambda=1.82$ \\
$22 \mathrm{~cm}$ of iron ... & $(22 \times 22) \mathrm{cm}$. & $\lambda=1.96$ \\
\hline
\end{tabular}

through $2 \mathrm{~cm}$. of iron is the same as that passing through $10 \mathrm{~cm}$. of carbon. For any position of the electroscope this equality of ratio seems to hold true. This points to the conclusion that the secondary radiation is the primary radiation scattered. If the radiation was a true secondary radiation it would be expected that the quality would depend on the material.

In the second table it is shown that an increase in area of the radiator causes the secondary radiation to become softer. This is no doubt due to the fact that as the area increases, a more obiique secondary radiation will come from the radiator.

\section{Effect of Screens round Radium.}

Experiments were made to examine the effect of different screens round the radium. The electroscope was $3 \mathrm{~mm}$. thick, and $8.75 \mathrm{~mm}$. of lead was used as an absorbing screen.

\begin{tabular}{c|c|c|c|}
\hline Radiator. & Thickness. & Radium unscreene.d. & Screened. \\
\cline { 1 - 3 } & $10 \mathrm{~cm}$. & $\lambda=268$ & $\lambda=2 \cdot 37$ \\
Carion ......... & $\lambda=160$ & $\lambda=1 \cdot 40$ \\
\hline
\end{tabular}


Two narrow blocks of lead, each $1.5 \mathrm{~cm}$. thick, were used as screens to the 300 mgrs. of $\mathrm{RaBr}_{2}$. The position of the electroscope was at right angles to the normal.

From the table it is seen that the screen has a hardening effect. Similarly it was shown that any other screen always had a hardening effect. The ratio of the absorption coefficients remains the same for each radiator, and the resnlts go to show that this ratio keeps constant for each position of tho electroscope.

Lead has always been used as the absorbing screen in these experiments, as the changes in coefficient of absorption are much more marked than with any of the lighter substances. Yet similar results are given for screens of iron or zinc. It is well known that lead will cut out the soft radiation to a much greater extent than iron. This holds for the secondary $\gamma$-rays as well as for the primary.

\begin{tabular}{|c|c|c|c|c|}
\hline Radiator. & $875 \mathrm{~cm}$. of $\mathrm{Pb}$. & $1.05 \mathrm{~cm}$ of $\mathrm{Fe}$. & $875 \mathrm{~cm}$. of $\mathrm{Pb}$ & $1.05 \mathrm{~cm}$ of $\mathrm{Fe}$. \\
\hline $10 \mathrm{~cm}$. of $\mathrm{C} \ldots$ & $\lambda_{\mathrm{Pb}}=70$ & $\lambda_{\mathrm{Fe}}=-28$ & $\lambda_{\mathrm{Pb}}=2.68$ & $\lambda_{\mathrm{Fe}}={ }^{\circ} \overline{6}$ \\
\hline $25 \mathrm{~cm}$. of $\mathrm{Pb} \ldots$ & $\lambda_{\mathrm{Pb}}=\cdot 46$ & $\lambda_{\mathrm{Fe}}=\cdot 24$ & $\lambda_{\mathrm{Pb}}=1 \cdot 60$ & $\lambda_{\mathrm{Fe}}=\cdot 49$ \\
\hline & \multicolumn{2}{|c|}{ Direct Radiation. } & \multicolumn{2}{|c|}{ Electroscope turned through $90^{\circ}$} \\
\hline
\end{tabular}

The absorption coefficient is first determined for $875 \mathrm{~cm}$. of lead, then for $1.05 \mathrm{~cm}$. of iron. Hence, while the absorption coefficient of the radiation changes from $\cdot 70$ to $2 \cdot 68$ when measured by $875 \mathrm{~cm}$. of lead, it only changes from .28 to $\cdot 56$ in the case of iron. Carbon shows this effect to a less extent than iron.

All metals will send out a radiation of the same quality provided the right thickness of radiator is used.

\section{Incident secondary $\gamma$-rays.}

A few experiments were carried out on the radiation emitted from the surface of the plate against which the primary rays strike. This radiation from iron and lead was softer than the emergent secondary radiation. This suggests that the softest radiation is most scattered. This incident radiation is similar in type to the emergent secondary and to the primary radiation. 
Summary.

(1) Secondary $\gamma$-rays are emitted from both sides of a plate exposed to $\gamma$-rays. The "incident" secondary is in all cases softer than the "emergent" secondary. There is, moreover, a gradual change from the quality of the primary to that of the secondiry emergent, and then to that of the secondary incident. The quality therefore depends on the position of the electroscope.

(2) An increase in area of the radiator softens the secondary radiation, $i$. e. the quality depends on area of radiator.

(3) An increase in thickness of the radiator produces a hardening of the primary and of the secondary emergent radiation. The quality depends on thickness of radiator.

(4) For radiators of different material the quality varies. But if the right thickness for each radiator is chosen, then the quality of the primary and secondary radiation is independent of the material of radiator. With any two radiators the ratio of the absorption coefficients keeps approximately constant for any position of the electroscope.

(5) The effect of screening the radium is to harden the secondary. The sereen seems to harden the secondary radiation from carbon in the same proportion as it hardens the secondary from lead. This hardening is also proportional to the hardening of the primary as measured by the absorption coefficient.

(6) The secondary radiation is heterogeneous, and this supports the view that the primary radiation is heterogeneous.

(7) There is a gradual decrease in the quantity of secondary $\gamma$ radiation from that which emerges from the radiator in the direction of the original radiation to that which is returned in the reverse direction.

(8) The curves showing the relation between quantity of secondary radiation and thickness of radiator change gradually in form for each successive position of the electroscope round the arc of a circle.

(9) The lighter materials produce more secondary $\gamma$ radiation than the heavier materials. A greater weight, however, is required of the lighter materials before the maximum amount is reached.

\section{Discussion of the Results.}

In the foregoing results there is nothing to suggest that the secondary $\gamma$ radiation is a true secondary excited in the material of the radiator by a transformation of the primary rays. In such a case it would be expected that each element

Phil. Mag. S. 6. Vol. 20. No. 120. Dec. 1910. 3 Q 


\section{Dr. J. W. Nicholson on the Approximate Calculation}

would give out a characteristic radiation. Experiments show that with proper conditions every substance can be so chosen as to give a similar type of radiation. It is important to notice that Bragg and Madsen (Phil. Mag. Oct. 1908) have shown that the character of the $\beta$ radiation caused by $\gamma$-rays is independent of the atom in which it arises, and depends solely on the nature of the $\gamma$-rays to which it is due. The present investigation shows that this is also true for the secondary $\gamma$ radiation.

The quality of the secondary $\gamma$ radiation shows no sudden change from that of the primary. There is simply a gradual softening the more the secondary radiation is deflected from its original direction. The gradual softening is the same for every radiator. Other investigators have shown that $\beta$-rays are scattered in their passage through matter. The scattering of $\gamma$ rays appears to be aralogous to the scattering of $\beta$-rays. The primary $\gamma$-rays possess a wide range of penetrating power. The softening of the secondary radiation that has been observed is the result of this heterogeneity of the primary rays. The softer radiation is more scattered than the harder radiation; as the radiator is increased in thickness more of the harder gets turned aside, and in consequence we get both the hardening of the primary and of the secondary. The hardening is due in the one case to the cutting out of the softer radiation, and in the case of the secondary to the addition of a more penetrating scattered radiation. There is no evidence of selective absorption. The production of this secondary $\gamma$ radiation is undoubtedly a scattering effect, as Madsen had concluded from previous experiments.

I desire to thank Professor Rutherford for the use of large quantities of radium and of radium emanation, and also for his suggestions in the course of this work.

Physical Laboratories, Manehester.

CV. The Approximate Calculation of Bessel Functions of Imaginary Argument. By J. W. NICHOLSON, M.A., D.Sc.* TN the British Association Report for 1908, some formulæ 1 were given suitable for the rapid tabulation of Bessel functions whose argument is purely imaginary and large, and whose order may be of any magnitude. The same results apply if the order is large, and the argument of any magnitude. A proof was not appended, and the object of the

* Conmunicated by the Author. 